Sección uno: Ensayo

Educación y Exclusión social

\title{
Justicia Restaurativa: la evasión no violenta como un nuevo supuesto de remisión ${ }^{1}$
}

Restorative Justice: the non-violent evasion as a new assumption of remission

Ian Medina Salas

Universidad de Lima

Ministerio del Interior del Perú

ian.mds1@gmail.com

\section{Resumen}

La sociedad ajena al origen, tratamiento y fundamento de la criminalidad, ha concertado en la necesidad del encierro para ciertas personas con la finalidad de contener una posible amenaza y evitar mayores contravenciones a determinados bienes jurídicos que permiten el desarrollo de la persona. En algunos casos, sin importar en las consecuencias contraproducentes generadas por esta postura, los castigos son efectivos, certeros y duraderos frente a la vulneración de algún riesgo prohibido. En aquel contexto, esta investigación atiende un fenómeno relevante propio del internamiento en medio cerrado: la fuga de los Centros Juveniles de Diagnóstico y Rehabilitación del Perú. Dicha premisa asume mayor relevancia para la teoría penal y criminológica, cuando aquella conducta de fuga, es realizada sin violencia por un adolescente interno en un medio cerrado por cometer una infracción que no revistió gravedad.

Palabras clave: Justicia Restaurativa, Remisión, Evasión, Estado de necesidad, Sanción penal

Keywords: Restorative Justice, Remission, Escape, Justifying state of need, Penalty sanction

\section{Abstract}

The society with little knowledge of the origin, treatment and basis of criminality, has agreed on the need to punish the confinement of people in order to contain a possible threat and prevent further violations of certain legal rights that allow the development of people. In

${ }^{1}$ Recibido: 09/05/ 2018 Evaluado: 15/06/2018 Aceptado: 20/07/2018 
some cases, regardless of the counterproductive consequences generated by this position, the punishments are effective, accurate and durable against the violation of any prohibited risk. In that context, this investigation addresses a relevant phenomenon of the confinement: the escape of juvenile prisons in Peru. This premise assumes greater relevance for criminal law and criminology, when that escape behavior is carried out without violence by a teenager who committed an infraction that was non-serious violation.

\section{Planteamiento}

Para el año 2017 se evadieron del encierro 37 jóvenes en conflicto con la ley penal de los distintos Centros Juveniles de Diagnóstico y Rehabilitación del Perú. En el periodo comprendido en los años 2010 - 2017, se registraron 232 fugas a nivel nacional, 46 de ellas fueron realizadas sin violencia o amenaza alguna (Administración de Centros Juveniles del Perú, comunicación personal, 5 de marzo del 2018). Los adolescentes que evadieron sin violencia, buscaron recuperar la libertad sin procurar ningún daño; sin embargo y pese que dicha conducta es atípica para el ordenamiento penal vigente, el Estado, mediante el órgano administrativo encargado de los Centros Juveniles, castiga dicha conducta con mecanismos muy severos y proscritos en un Estado de derecho.

Resulta necesario añadir que, durante la investigación que fundamenta este artículo, se encontró que muchos jóvenes que fugaban sin violencia eran recapturados (en la mayoría de los casos) en sus hogares. Realidad que dista mucho de los prejuicios formados en sociedad que esperan una recaptura realizada en medio de una pandilla, en algún bar o discoteca. (Administración de Centros Juveniles del Perú, comunicación personal, 23 de enero del 2017).

Aquellos hechos fundamentales, la fuga, la respuesta estatal y el contexto que rodea las circunstancias personales y de situación de los jóvenes que escapan sin violencia, son piezas esenciales para lograr una respuesta eficiente y legítima que procure aciertos en nuestra sociedad.

Dichos criterios fueron los que motivaron a investigar mencionadas situaciones y características, determinando la siguiente postura que será fundamentada en el presente artículo: no se debe perseguir o recapturar a aquel joven (interno por cometer una infracción no gravosa) que, guiado por su instinto de búsqueda de la libertad, se evade sin violencia del medio cerrado; toda vez que resulta más beneficioso dejarlo en libertad y darle la oportunidad que se resocialice en sociedad. Este supuesto mantiene una correspondencia con la Remisión, producto de la Justicia Restaurativa que es utilizada para alejar del proceso judicial y del internamiento en medio cerrado a los jóvenes en conflicto con la ley penal.

Cabe mencionar, que la propuesta, bajo una óptica criminológica, pretende cortar la subcultura carcelaria, el contacto diferencial, mitigar el etiquetamiento, y brindar una oportunidad de valor para alejar del medio nocivo a la persona (joven infractor) que se encuentra en el encierro; esto último amparado en los principios que desarrollan las teorías del desistimiento delictivo.

En suma, el presente estudio afirma que es más beneficioso mantener alejado a un joven infractor del medio cerrado, toda vez que supone una acción positiva para la sociedad; máxime cuando la infracción que cometió el adolescente no es gravosa y el objeto material es recuperable o reparable.

Por tanto, este artículo desarrollará tres ejes principales, el primero encargado de comentar el desafío que representa esta postura frente al moralismo legal que entiende como 
beneficiosa a la herramienta de castigo. En un segundo ámbito, se describirá la conducta de autoprotección que supone una evasión del castigo penal (estado de necesidad), en tercer lugar, se determinará cómo el comportamiento de evasión de un medio cerrado sin violencia, representa una oportunidad para aplicar una herramienta que se fundamenta en el paradigma de la Justicia Restaurativa.

Cabe mencionar que esta propuesta se ampara en la óptica criminológica del encierro que determina sus efectos nocivos, la evasión sin violencia como un punto de inflexión de la actividad criminal, y los severos daños de aislamiento y tortura que soportan los jóvenes que viven en un contexto donde existe un exacerbado hacinamiento.

El afán del estudio se fundamenta en brindar una opción eficiente para disminuir los índices de reincidencia y la futura producción de nuevos comportamientos desviados; de esa manera, se podrá mitigar los daños que sufre la sociedad y también podemos alertar, denunciar y reducir la tolerancia que se desarrolla en torno a los abusos que se cometen en contra de la población de jóvenes privados de libertad.

\section{Un desafío para el moralismo legal}

El moralismo legal imperante en nuestro tiempo y espacio, asume que no es adecuado dar libertad al que fuga. El discurso actual define al encierro como beneficioso, se estima que las mecánicas nocivas y contrariedades son menores a la sensación temporal de seguridad.

La sociedad considera que albergar personas que cometen actos criminales en centros penitenciarios (se incluyen los Centros Juveniles de Diagnóstico y Rehabilitación) genera beneficios; por tanto, si algún joven infractor escapa de estos lugares automáticamente se genera un prejuicio. Se considera que el comportamiento de fuga es merecedor de un castigo, pese a que esta conducta forma parte de la libertad jurídicamente garantizada; es decir, permitida. Sin embargo, no se toma en cuenta que la medida socio-educativa de internamiento en medio cerrado envuelve al adolescente en un ambiente hacinado, violento y poco atendido por el Estado (Roxin, 2000).

El progreso del derecho se fundamenta en la búsqueda de soluciones jurídicas a los nuevos problemas, o a los añejos no resueltos. Por ello es necesario idear opciones acertadas frente al fenómeno de fuga. Cabe indicar que la recaptura, derivada de una fuga no violenta, incluye un aleccionamiento feroz para los jóvenes evadidos, mediante golpes con madera sobre las manos y en las plantas de los pies, malos tratos, reducción ilegal de derechos y la colocación en lugares diseñados y empleados para el aislamiento, todo ello forma parte del parte de la respuesta administrativa frente a una evasión sin violencia.

Por tanto, todo adolescente que intenta o logra su cometido de fuga es merecedor de un castigo en aislamiento por 3 meses. De las visitas realizadas en enero del 2017 a los Centros Juveniles de Diagnóstico y Rehabilitación de Lima, tanto de hombres como de mujeres, se comprobó que, en el caso de las adolescentes, el aislamiento comprendía habitaciones ínfimas con una pequeña entrada de aire y luz, cama de cemento sin colchón. Este castigo permite que se prohíban las visitas, la asistencia a programas y la restricción de ciertos alimentos. La respuesta estatal frente a una conducta que se desarrolla por el instinto de búsqueda de la libertad no es adecuada, “... se trataría de una simple y burda retribución carente de sentido valorativo y proscrita en un Estado de Derecho" (Meini, 2013, p.167).

$\mathrm{N}^{\mathrm{0}} 7,2019$. Página| 16 
En ese sentido, es necesario entender que el medio cerrado alberga más contrariedades que beneficios, y la evasión sin violencia de estos lugares supone una alternativa. Es una oportunidad donde el joven no está expuesto a vulneraciones sistemáticas y constantes, que solo ocasionan o generan a una persona con escasos niveles de empatía y con códigos de conducta que son fundados en la violencia y la coerción.

\section{Respecto al estado de necesidad presente en la evasión no violenta}

Se deben considerar dos principios aplicables en la conducta de evasión no violenta de un Centro Juvenil de medio cerrado. El Principio de Protección Individual, entendido por la defensa de bienes jurídicos individuales (vida, integridad física y psicológica, salud, etc.) y el Principio de Prevalecimiento del Derecho que Roxin define de la siguiente manera:

Es decir, todo el mundo tiene el derecho a defenderse de ataques prohibidos de tal manera que no sufra ningún daño. Pero también allí donde puede sustraerse al ataque le está permitido siempre defenderse legítimamente. El principio de prevalencia del Derecho (la idea, por tanto, de que el Derecho no tiene que ceder ante el injusto) va más lejos aquí que los intereses de autoprotección y, desplaza también al principio de ponderación de bienes que, por lo demás, tiene a menudo decisiva importancia en las causas de justificación.

(Roxin, 2000, p.78).

En ese sentido, frente una agresión antijurídica, es posible repeler el ataque de manera legítima, ello estabilizará el orden jurídico. Se busca el prevalecimiento del derecho con racionalidad, es decir -en la medida de lo posible- sin violencia (Roxin, 2000, p.251). "A nadie se le puede oponer dificultad alguna para que, viéndose víctima de una acometida incalificable, trate de repeler la fuerza con la fuerza" (Roxin, 2000, p.252).

Para el caso de estudio, se pudo constatar (mediante entrevistas al personal administrativo de los Centros Juveniles y a un ex infractor que estuvo interno) el empleo sistemático de violencia, los malos tratos y los abusos de poder por parte del personal administrativo y de los infractores que conviven en un ambiente de agresividad y coerción violenta. "Pero inversamente la pirámide carcelaria da al poder de infligir castigos legales un contexto en el cual aparece como liderado de todo exceso y de toda violencia. Lo carcelario "naturaliza" el poder legal de castigar, como "legaliza" el poder técnico de disciplinar" (Foucault, 1999, p.309).

Las condiciones de internamiento que ofrecen los Centros Juveniles de Diagnóstico y Rehabilitación son ilegítimas, mantienen un alto nivel de hacinamiento y las acciones que se desarrollan a causa de las fugas son contrarias a lo razonable. En tanto el hacinamiento, en el 88.8\% del total de los Centros Juveniles de Diagnóstico y Rehabilitación de medio cerrado, existe un hacinamiento mayor al $40 \%$, evidenciando incluso niveles muy altos que bordean el $220 \%$ de hacinamiento en el Centro Juvenil de Diagnóstico y Rehabilitación de Trujillo (Consejo Nacional de Política Criminal, 2017, p.14). 
En una situación de fuga (violenta o no) y posterior recaptura, se permite una ración de golpes físicos sobre el cuerpo de los jóvenes infractores recapturados, se dispone su aislamiento donde son víctimas de actos que pueden ser catalogados como tortura. El ataque resulta actual, constante y persistente en aquellos centros de medio cerrado. La defensa frente a la situación antijurídica que se presenta en los Centros Juveniles debe emplear medios suficientes para repeler dicho contexto vulnerador; es decir, existe una necesidad racional en el medio empleado para la neutralizar la acción ilegítima. (Armaza Galdós, 2004).

Son por estas razones que el Derecho debe prevalecer frente a la afectación de bienes jurídicos como la dignidad, salud, integridad física y/o psicológica, la vida, etc. Se debe entender como un acto de autoprotección al escape no violento de estos centros donde existe una vulneración constante y progresiva en los derechos fundamentales de los jóvenes en conflicto con la ley penal. Los jóvenes que se encuentran en el medio cerrado se exponen a altos grados de hacinamiento, lugares especializados para castigar el cuerpo y mecánicas que albergan prácticas nocivas; en un contexto similar, salir o escapar de este lugar, no solo es permitido, sino, necesario.

\section{Una oportunidad derivada de la Justicia Restaurativa}

Un diferente sector influenciado por el escepticismo de la utilidad de la privación de la libertad, apostó por una medida restaurativa, donde la víctima, el delincuente y la comunidad serían los actores principales de la reforma. Es decir, el modelo conocido e imperante aún en el Perú, de Justicia Retributiva, debería de mutar para convertirse en una de Justicia Restaurativa, donde la víctima es la principal afectada y ella tiene que ser reparada, y reintegrada a la Sociedad; además, debe existir la seguridad que no vuelva a suceder una futura y adicional victimización (Llobet, 2005).

El primer proyecto de Justicia Restaurativa se llevó a cabo en Ontario-Kitchener, en él unos jóvenes dañaron 22 propiedades (Llobet, 2005), y se produjeron actos de vandalismo. Se trabajó con los fundamentos de esta justicia y se logró que los jóvenes reconocieran su responsabilidad, se evitó que los adolescentes ingresaran al sistema penal, pero sí pudieron realizarse reuniones donde la víctima explicaba los daños, demostraba sus sentimientos y de esa manera el transgresor de la norma podía entender la magnitud del daño. En seguida, se buscó que los jóvenes repararan los daños causados, no obstante, no podían reparar los 22 hogares puesto que no contaban con los recursos suficientes. Por ello, la comunidad, brindó las herramientas necesarias para que los jóvenes cumplieran su propósito. Al realizar la conducta de reparación, los adolescentes pudieron conocer el esfuerzo, tiempo y dedicación que demandaba la creación y cuidado de la propiedad.

Una vez finalizada la labor, el daño queda reparado, la víctima conoce las razones, acepta las disculpas y es reintegrada a la sociedad (la víctima entiende que el joven infractor es producto de la comunidad en la que ella vive y se desarrolla). Asimismo, el adolescente no queda expuesto a ningún contacto con el sistema penal, sin estigmatización ni antecedentes. No existen estigmas que acompañen al infractor durante la ejecución reparadora, es también un modo de aprendizaje eficaz. Se evita el efecto etiquetador de la privación de la libertad (Llobet, 2005). 
En ese sentido, las corrientes restaurativas incluyen un modelo integral donde están presentes las víctimas, agresores y la comunidad. Estos tres actores, son esenciales para que la Justicia Restaurativa funcione. La víctima deberá ser reparada, el agresor deberá entender y mitigar el daño causado y la comunidad tendrá la responsabilidad de detectar por qué el agresor cometió un daño y qué hacer para que no se vuelva a reiterar. De esa manera, se podrá prevenir la comisión de nuevas infracciones, se romperá la cadena de etiquetamiento, estigmatización y se crearán círculos virtuosos de renovación automática.

A propósito, Liebmann señala que: “[...] el énfasis circunda la reparación de la víctima y de la comunidad en lugar de castigar al agresor. [...]La justicia restaurativa aspira restaurar el bienestar de las víctimas, los agresores y la comunidad dañadas por el crimen, y así prevenir mayores ofensas" (Liebmann, 2007, p.25).

Para Liebmann, la Justicia Restaurativa puede ser entendida como una postura en contra del castigo, que restaura a la víctima y a la comunidad. Explica que la persona que vulnera la norma debe conocer el impacto del daño cometido, y de esa manera (comunidad y víctima) brinden una oportunidad para reparar el bien jurídico que resultó mermado. Es una justicia que transforma, ya que se puede mutar el delito/infracción en algo diferente, y la experiencia traumática puede resultar en sanadora para ambos -delincuente y víctima- (Liebmann, 2007). Liebmann en aquel contexto, explica que los beneficios derivados de la actividad restaurativa mantienen los 4 actores principales de la actividad criminal. La víctima es beneficiada porque conoce los motivos del daño, recibe disculpas, pregunta razones, se da cuenta del conflicto, recupera el objeto material sobre el cual recae el bien jurídico (para ciertos casos) y supera el crimen. El beneficio para el delincuente/infractor se produce cuando entiende el dolor de la víctima, percibe las consecuencias de su actividad y acepta de manera responsable su autoría, pide perdón y/o repara, mejora su futuro. Para las cortes el beneficio también es notable, ya que existirá más conciencia en el castigo y ello generará sentencias más realistas, conocerán cómo son afectadas las víctimas y les brindarán un papel preponderante en el sistema. Finalmente, la comunidad también se beneficia, pues elimina de su praxis a la violencia y al castigo, acepta al perdón y/o reparación y ayuda con la labor reintegradora, tanto del sujeto activo como del pasivo (Liebmann, 2007).

Se resalta que esta medida es optativa en la mayoría de los sistemas de control formal; sin embargo, mantiene el carácter de obligatorio en Austria, Nueva Zelanda y Noruega; en aquellos países el sistema judicial formal solo se activará cuando la Justicia Restaurativa no funcione (Liebmann, 2007). "El desafío es superar la lógica del castigo, pasando a una lectura relacional del fenómeno criminal, entendido primariamente como un conflicto que provoca la ruptura de expectativas sociales simbólicamente compartidas” (Rita Mill, 2013, p.216).

\section{Remisión}

La Remisión es una herramienta de la Justicia Restaurativa, aleja al infractor del sistema penal y brinda una oportunidad de resocialización en libertad. "[...] funciona dentro de los criterios de oportunidad como alternativa al proceso judicial en sí mismo (mecanismo de diversión, desformalización o desjudicialización) y además, como auténtica salida alternativa frente a la respuesta punitiva, que de iniciarse y culminar el proceso judicial probablemente le sería impuesta" (Hernández, 2012, p.237). 
La Remisión tiene como meta evitar que el adolescente infractor ingrese al sistema penal. Existen tres requisitos por los cuales el adolescente debe ser separado de la medida internamiento.

(i) Infracciones que no revistan gravedad.

(ii) Compromiso del adolescente infractor de concurrir a programas de orientación.

(iii) Reparar a la víctima.

En esencia, la Remisión se caracteriza por crear un estímulo positivo y disminuir la severidad y el castigo contraproducente. Se considera que dichos estímulos construyen conocimientos ya que reparan un daño, y de esa manera reconfortan a la víctima. La Remisión se convierte en una experiencia gratificante que envuelve un aprendizaje, enmienda errores y compensa positivamente a otros por los daños ocasionados.

Gráfico 1.1. Medidas socioeducativas impuestas a los adolescentes en conflicto con la ley penal

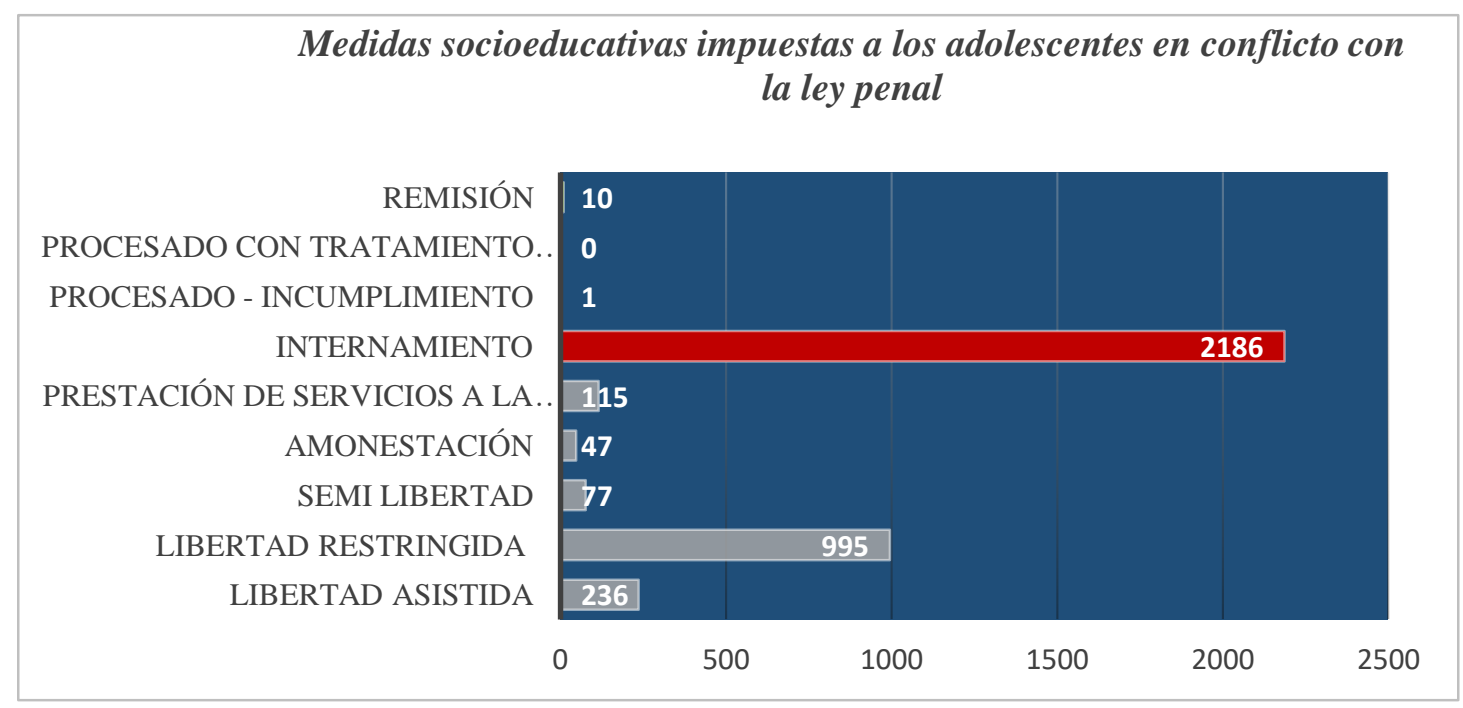

Fuente: Poder Judicial. Gerencia de Centros Juveniles. (2017). Tipo de medidas socioeducativas según sistema cerrado - sistema abierto. Informe estadístico 2017. Lima: Oficina de imagen institucional. Pág. 19.

La estadística evidencia que la Remisión judicial, destinada a favorecer a los adolescentes en conflicto con la ley penal, no es empleada por los operadores de justicia. De un universo de 3, 674 jóvenes infractores de la ley penal en febrero del año 2017, la Remisión benefició solo a 10 adolescentes. Ello quiere decir que la utilización de la medida Remisión representa solo el $0.27 \%$ de la población de jóvenes en conflicto con la ley penal. Por tanto, se puede afirmar que los Jueces de Perú no conocen o no consideran relevante ni útil la medida de Justicia Restaurativa; toda vez que menos del $1 \%$ (0.27\%) de los jóvenes infractores han podido obtener una medida socioeducativa amparada en los criterios de esta herramienta.

Frente a ello, cabe mencionar que de manera ilegítima también se imponen medidas socioeducativas de internamiento a adolescentes que cometieron infracciones sin gravedad. Existen jóvenes encerrados por cometer hurto, representado por el $8.5 \%$ de la población 
juvenil encerrada (Consejo Nacional de Política Criminal, 2017, p.23). Jóvenes internos que cometieron una infracción donde no existe violencia o amenaza y la naturaleza del bien jurídico es patrimonial, y por ende, recuperable.

Es en este contexto, de internamiento ilegítimo, en el que se propone aplicar la remisión al adolescente que evade sin violencia del medio cerrado. Ello incluirá la posibilidad de no ejercer la recaptura, y en caso que se le recapture, se pueda aplicar de manera obligatoria una evaluación para implementar el mecanismo de justicia restaurativa en el caso específico; situación que brindará la posibilidad de reparar el daño, reintegrar a la víctima y permitir que el infractor permanezca libre en sociedad, sin tener que afrontar el proceso de aprendizaje de conductas delictivas y estigmatización del Proceso Penal.

Aplicar el nuevo supuesto de Remisión a un joven que obedece a su instinto de búsqueda de la libertad y que a su vez no ha cometido una infracción que atente contra esas tres garantías mínimas (vida, cuerpo, libertad) merece la aplicación de la Remisión que representa una oportunidad, una alternativa que aleja al infractor del Sistema Penal, de la vida delictiva y evita la convivencia con lo más violento y nocivo de nuestro medio. "Precisamente la libertad es tan importante, porque no sabemos cómo la utilizarán los individuos" (Hayek, 2014, pp.58-59). Para Hayek además:

El individuo goza de soberanía y, aunque parte de lo que es se explica por el medio en que nace y se forma, hay en él una conciencia y un poder de iniciativa que lo emancipan de esa placenta gregaria y le permiten actuar libremente, de acuerdo a su vocación y talento, y a menudo, imprimir una huella en el entorno en el que vive. (Vargas Llosa, 2018, p.111).

\section{Supuesto adicional de remisión por evasión no violenta}

La propuesta central de esta investigación se concentra en atender un supuesto adicional en la aplicación de la Remisión. El propósito que la Remisión persigue, es alejar al joven infractor del sistema penal; toda vez que esta institución considera que el encierro representa un medio nocivo para el desarrollo del adolescente. El legislador no desea insertar en un medio cerrado a una persona que no haya cometido infracciones graves. En consecuencia, el nuevo supuesto de Remisión permite que el adolescente no violento, que no cometió una infracción que revista gravedad y que -influido por su instinto de recuperación de libertadescape sin violencia del medio cerrado, también pueda ser evaluado en los mismos preceptos y condiciones que mantiene la remisión para determinar si es necesario alejar del sistema penal al adolescente fugado sin violencia.

Los preceptos rectores son los mismos (evitar estigmatización, infracción no grave, rehabilitación en comunidad), el único elemento que adiciona este nuevo supuesto de la remisión, es la fuga no violenta realizada por el adolescente interno. Es decir, será posible evaluar la condición del joven, en caso éste se evada de un Centro Juvenil de Diagnóstico y Rehabilitación; en aquel contexto, se debe considerar nuevamente las finalidades y requisitos de la remisión. De esa manera, con una nueva evaluación, el fugado pueda ser separado de manera inmediata del sistema penal y cumplir con los fines de la justicia restaurativa.

Todo ello, en atención a que no es una conducta delictiva escapar de un medio cerrado, es más bien, una conducta que forma parte de la libertad jurídicamente garantizada y entendida además como condición humana; toda persona que se encuentre sometida a un encierro (legal o ilegítimo) anhelará recuperar la libertad. Este deseo de escape se ve acrecentado por el castigo desatento y desproporcional del Operador de Justicia que no empleó la Remisión a su debido tiempo y oportunidad. 
No cabe castigar cuando, a tenor de las circunstancias concurrentes en concreto, no resulte razonable exigir al sujeto una conducta distinta a la que realizó. Y no es exigible porque el derecho no puede esperar que nadie resista a una posición motivacional excepcional. La no exigibilidad deja, así, incólume la antijuridicidad, que va referida a comportamientos no deseados por el derecho. (Terradillos, 2004, p.38-39).

La exclusión del clima hostil, que representa esta nueva hipótesis de remisión, mantiene solo una característica adicional: Fuga no violenta realizada por un adolescente que se encontraba interno por cometer una infracción considerada como no grave. Es posible reforzar a la Remisión con esta nueva característica ya que incluye (aparte de cumplir con todos los presupuestos dados en la norma Decreto Legislativo núm. 1348, del 6 de enero del 2017) una conducta de escape no violenta, generada por una acción de autoprotección y motivada por el instinto humano.

En cierta medida esta nueva remisión acepta que tanto el Fiscal como el Operario de la ley penal (Juez) puedan reevaluar la aplicación de la Remisión del adolescente del sistema penal. Es una nueva oportunidad, que deberá servir para observar y cumplir con los requisitos y obligaciones que determina la Remisión, ya que de esa manera (según se cumplan satisfactoriamente los supuestos que el Decreto Legislativo núm. 1348) sería posible separar del Sistema Penal al joven no peligroso, fugado sin violencia, de un Centro Juvenil de Diagnóstico y Rehabilitación.

Ni la venganza de la ofensa hecha a la sociedad, ni la expiación del delito son los objetos de las penas. La venganza es una pasión, y las leyes están exentas de ella [...]. El objeto pues de las leyes, cuando castigan los delitos, no puede ser sino impedir que el delincuente haga otros daños a la sociedad, y retraer a los demás de imitar su ejemplo, por medio de la impresión que debe causar en sus ánimos la pena que él padece: y si se puede conseguir este fin con las penas más suaves, no deben emplearse las más severas [...]. Si no se contiene en estos límites, cae en la tiranía [...]. (Filangieri, 1823, pp.323-324).

Una salida oportuna ocasionada por una fuga, representa tres beneficios:

a) Acepta y reconoce un efecto inherente al encierro: la búsqueda constante de libertad,

b) Brinda a la comunidad la capacidad de eliminar la posibilidad de que el criminal adolescente obtenga mayor experiencia e información respecto a variados crímenes, y finalmente,

c) Ofrece una oportunidad para que los jóvenes infractores tengan mayor probabilidad de reinsertarse a la sociedad.

Asimismo, este nuevo supuesto de Remisión busca impedir el efecto "puerta giratoria". En dicho efecto, las personas que entran al medio cerrado reingresan con mucha facilidad al contexto de encierro, pierden lazos sociales, experiencia laboral, se incrementa su nivel de vulnerabilidad y los factores de riesgo se ven multiplicados. Al salir del encierro, se convierten en "ciudadanos de segunda clase" etiquetados y marginales. En aquel escenario, cuando la medida de internamiento termina, el grupo mayoritario vuelve a reincidir. De esa manera el medio cerrado se convierte en una constante, llena de reingresos; en aquel contexto es muy difícil reintegrarse a la sociedad (McNeill, Farrall, Maruna, 2012).

La tupida celosía en la que se desarrolla el sistema de justicia dificulta su tarea, observar el problema con claridad es un reto y el legislador, empujado por la opinión pública derivada a veces por la prensa no objetiva, solo incrementa el riesgo para las víctimas. 
Creo firmemente que los castigos severos y las penas efectivas no representan la solución para combatir nuestro índice de criminalidad o sistema de seguridad; tiene el efecto contrario, lo especializa y difunde.

[...] el proceso de secularización del Derecho y de la Filosofía Penal está en la base, o al menos, representa un estímulo para la tesis que concibe la desviación criminal, no como la expresión de una enfermedad moral, sino como la consecuencia de una mala organización de la sociedad y que, por tanto, resulta más eficaz y razonable poner remedio a sus causas que hacer uso de la fuerza; en otras palabras, que el Código Penal, el más cruel de los instrumentos estatales, no es el único ni seguramente el más adecuado modo de combatir la delincuencia, que muchas veces no llegaría a exteriorizarse con una adecuada prevención; así, en lugar de condenar a muerte a la mujer infanticida que deja morir al hijo para ocultar su deshonra, valdría más crear hospitales donde pudiera dar a luz secretamente. (Pietro Sanchís, 2007, p.88).

\section{Límites racionales de la propuesta}

Toda conducta relevante para el derecho penal está investida dentro de los límites que determinan su naturaleza y utilidad. Por ello, es menester determinar cuál es el ámbito de acción de la nueva Remisión, ello evita la generación de excesos o malos usos; además ampliará sus beneficios, siempre y cuando, se mantenga una dirección alineada a reducir los índices de criminalidad: En ese sentido dividiremos los límites en dos grandes grupos, el primero referido a la naturaleza del bien jurídico protegido que fue dañado, y el segundo, definido por la conducta que el adolescente realiza con el propósito de obtener su libertad; es decir, externalización de su instinto de búsqueda de la libertad. Por tanto:

La infracción que reviste gravedad será la que merece el internamiento (de ultima ratio) del joven en un medio cerrado. Por tanto, la conducta que vulnera un riesgo prohibido debe ser dolosa y el tipo penal debe establecer para aquella contravención una pena no menor de 6 años, siempre que haya puesto deliberadamente en grave riesgo la vida o la integridad física o psicológica de las personas. "Presupuestos de la internación: [...] 1. Cuando se trate de hechos tipificados como delitos dolosos [...], con pena privativa de libertad no menor de seis (6) años, siempre que se haya puesto deliberadamente en grave riesgo la vida o la integridad física o psicológica de las personas.” (art. 162 inc.1 del Decreto Legislativo núm. 1348).

Me explico: un muchacho joven ingresa al reclusorio porque robó una miscelánea con una navaja. Se queda unos tres o cuatro años dentro de una prisión que, formal y nominalmente, tiene una oferta educativa, laboral y psicológica que lo "re-educará". En la práctica no lo hace y el joven se vuelve un sirviente de delincuentes peligrosos, que lo instruirán -y muy bien- en las malas artes y que, además, lo involucrarán en la droga. Al término de su estancia saldrá a la calle sin dinero, sin educación (no tiene oficio ni beneficio) con un estigma social -es un ex presidiario-, con un vicio acendrado y con un rencor inmenso. Ésta en peores condiciones que antes de entrar y tiene como referentes lo malo que aprendió en la cárcel. ¿Qué le queda? Lleno de anti-valores recurrirá al crimen como única vía, de fatalismo inconsciente en contra de... ¿quién? ¿Del funcionario poderoso con escoltas? No. En contra de un ciudadano decente que pagó sus impuestos para mantener un sistema de seguridad y uno de reinserción social efectivos que no resultaron, y ahora él o su familia recibirán ese golpe ciego, brutal e inmerecido del rencor, la violencia y la sinrazón. [...] Con una pena 
mayor -unos doce años- el joven tendrá una perspectiva diferente y se hará más violento, más cruel y más vicioso. Como tiene menos que perder, se vuelve más audaz y puede ascender en la escala estratificada del mal: será reclutado para delitos mayores por bandas mejor organizadas y que lo inducirán, al salir, a los delitos más ominosos y alarmantes, con la complicidad y la tutela policial, en contra, ¡claro!, de una sociedad que sigue pensando que lo malo o injusto o ineficiente que ocurra en las cárceles no es de su incumbencia, pero sí lo es. (Maldonado Manzanilla, 2010, p.82).

La propuesta asume que encerrar a un adolescente, que no cometió una infracción grave, en un ambiente muy riesgoso, cruel y violento (donde además estará desprotegido), lo expone a un contacto duradero e intenso donde es muy probable que aprenda conocimientos y experiencias criminales "...que es aprendido por asociación directa e indirecta con aquellas personas que ya practican el comportamiento" (Sutherland, 1940, p.10). Por ello, se busca generar una alternativa de escape, que mitigue aquellos efectos nocivos y pueda aplicarse la nueva remisión, máxime cuando se encuentra privado de libertad, un joven que no cometió una infracción grave.

Así también, una vía de escape justificada bajo el instinto de búsqueda de libertad no puede admitir ninguna cuota de violencia. Si representa un riesgo u ocasiona un daño, desvirtúa su propia utilidad.

V. En este contexto, el nuevo supuesto de remisión aprovecha los errores de la administración judicial, una mala defensa, exceso de castigo, ambiente nocivo, etc., y evita el efecto escuela que dificulta la posibilidad de recuperación del sujeto. Si no es necesario ni útil mantener a una persona en un centro de internamiento, entonces no se debe de utilizar al encierro como una medida educativa, pues el efecto a todas luces es contraproducente.

\section{Conclusiones}

- Es una práctica aceptada en el encierro, el tratamiento basado en la violencia mediante malos tratos, aislamiento disciplinario por un tiempo promedio de 3 meses. Este incluye el empleo de una severa violencia física y psicológica, no permite visitas, restringe ciertas comidas y prohíbe la salida a los espacios comunes.

- La conducta que propicia la evasión no violenta de un centro de rehabilitación forma parte de la libertad jurídicamente garantizada. Evadirse del encierro -aunque el internamiento fuera legítimo- no constituye delito (para los mayores) ni infracción penal (para los adolescentes); en tanto la fuga no fuera violenta.

- Negar oportunidades a las personas que trasgreden el ordenamiento penal reduce de manera considerable la posibilidad del crecimiento social, económico y moral.

- La medida socioeducativa de internamiento solo debe aplicarse para aquellos adolescentes que cometieron una infracción grave. Se debe entender por grave toda conducta dolosa que merezca pena privativa de libertad no menor de 6 años, siempre que se haya puesto deliberadamente en grave riesgo la vida o la integridad física o psicológica de las personas.

- El excesivo tiempo de encierro genera el aprendizaje de conductas criminales por intensidad y durabilidad en la convivencia.

- El continuo incremento del populismo penal genera exacerbados niveles de hacinamiento. Ocho de los nueve Centros Juveniles de Diagnóstico y Rehabilitación del Perú se encuentran con márgenes de hacinamiento, superiores al $40 \%$. 
- El principal objetivo (resocializador, rehabilitador y de reinserción) de los Centros Juveniles de Diagnóstico y Rehabilitación en el Perú ha mutado, de facto y de iure, por uno de contención.

- En internamiento, están afectados los derechos esenciales que la auto tutela (representada por la evasión no violenta) pretende poner a salvo o intenta cortar la cadena de afectaciones en curso. Evadirse de un medio cerrado, sin mediar violencia en la fuga, es entendido como un acto de autoprotección en un contexto de estado de necesidad.

- No es razonable que la Administración de los Centros Juveniles, reaccione ante la fuga no violenta, castigando la conducta de autoprotección que la evasión pacífica implica.

- La Justicia Restaurativa se erige sobre la Justicia Retributiva. La Justicia Restaurativa evita el etiquetamiento, el aprendizaje de conductas vulneradoras, el fenómeno "puerta giratoria" y mitiga el avance de la criminalidad. La Justicia Restaurativa procura la reparación del daño o recuperación del objeto material afectado; en ese sentido, dicha justicia debe ser aplicada para todos los supuestos donde el bien jurídico dañado pueda ser reparado por el adolescente infractor.

- Establecer puntos de inflexión en las personas que quieran desistir de la actividad criminal, ocasiona la implementación de medidas eficientes que solo generan beneficios al individuo y a la sociedad.

- La Remisión se presenta como una alternativa de resocialización sin que medie ningún tipo de violencia de parte del Sistema Penal. La Remisión representa una oportunidad de resocialización en sociedad, evita la imposición del internamiento en medio cerrado para aquellos jóvenes que cometieron ciertas infracciones de mínima lesividad. En caso de evasión no violenta se debe posibilitar la aplicación de la Remisión.

En consecuencia, se debe entender a la conducta de evasión no violenta como un acto de autoprotección frente a las graves vulneraciones que se desarrollan en un contexto de encierro. Además, es posible utilizar los criterios brindados por la Justicia Restaurativa para otorgar una oportunidad al joven que evade sin violencia, y de esa manera, aplicar lo determinado por la remisión. Resulta más beneficiosa una resocialización en libertad que un tratamiento nocivo, violento y hacinado, donde la probabilidad para aprender nuevas conductas delictivas es muy alta. Es necesario atender los puntos desarrollados en este artículo para observar de cerca cómo viven los jóvenes en conflicto con la ley penal y entender que la violencia genera mayores y profundos daños que retrasan a toda la sociedad.

\section{Referencias}

Armaza Galdós, J. (2004). Legítima defensa, error de comprensión y otros aspectos negativos del delito, Arequipa, Perú: Adrus.

Consejo Nacional De Política Criminal. (2017). Adolescentes infractores en el Perú. Boletín VI, Lima, Perú: Ministerio de Justicia y Derechos Humanos.

Filangieri, C. (1823). Ciencia de la Legislación. Recuperado de: https://goo.gl/7vtnvy

Foucault, M. (1999). Vigilar y Castigar. Nacimiento de la Prisión, México DF, México: Siglo Veintiuno Editores. 
Hayek, F. (2014). Los fundamentos de la libertad, Madrid, España: Unión Editorial.

Hernández Alarcón, C. (2012). Salidas alternativas y justicia restaurativa en la justicia penal juvenil, Lima, Perú: Gaceta Penal y Procesal Penal.

Liebmann, M. (2009). Restorative Justice: How it works, London, United Kingdom: Jessica Kingsley Publishers.

Llobet Rodríguez, J. (2005). Justicia restaurativa en la justicia penal juvenil, Buenos Aires, Argentina: Editores del Puerto.

Maldonado Manzanilla, L. (2010). Las paradojas de la libertad: una reflexión personal desde la ergástula, México DF, México: Fomento Cultural Grupo Salinas.

McNeill, F., Farrall, S. and Maruna, S. (2012). The Road from Crime. What can we learn from those former prisoners who have successfully "desisted" from criminal behaivour or "gone straight"? United Kingdom.: Iriss. Recuperado de: https://goo.gl/vdy5aQ

Meini, I. (2013). La pena: función y presupuestos, Lima, Perú: Pontificia Universidad Católica del Perú.

Merton, R. (1938). Social Structure and Anomie, Boston, United States of America: Harvard University. Recuperado de: https://goo.gl/BRiK6P

Mill, R. (2013). Mediación Penal, Buenos Aires, Argentina: Rubinzal - Culzoni.

Pietro Sanchís, L. (2007). La Filosofía Penal de la Ilustración, Lima, Perú: Palestra Editores.

Roxin, C. (2000). Política criminal y sistema de derecho penal, Buenos Aires, Argentina: Editorial Hammurabi SRL.

Sutherland, E. (1940). White-collar criminality, United States of America: American Sociological Review. Recuperado de: https://goo.gl/VVH1AX

Terradillos, J. (2004). Responsabilidad penal de menores, Valencia, España: Tirant lo Blanch.

Vargas Llosa, M. (2018). La llamada de la tribu. Lima, Perú: Alfaguara. 